\title{
Pelatihan Pembuatan Media Pembelajaran Menggunakan Video Animasi Guna Meningkatkan Penjualan di SMA Muhammadiyah 3 Surabaya
}

\author{
Lestari Retnawati \\ Universitas Wijaya Kusuma Surabaya
}

\author{
Firman Pratama \\ Universitas Wijaya Kusuma Surabaya
}

\author{
Tjatursari Widiartin \\ Universitas Wijaya Kusuma Surabaya
}

\author{
Nonot Wisnu Karyanto \\ Universitas Wijaya Kusuma Surabaya
}

\author{
Anang Kukuh Adisusilo \\ Universitas Wijaya Kusuma Surabaya
}

\begin{abstract}
Advances in science and technology also influence progress and developments in various fields, including education. Teachers must be able to create interesting learning and have the potential to create enthusiasm for student learning. Based on the results of initial identification to one of the teacher boards of SMA Muhammadiyah 3 Surabaya, it is known that one of the problems faced by teachers today is the difficulty in providing effective learning media. This can be realized using animated videos in learning. Learning media is the most important part of implementing learning evaluation activities. Animated video is an innovative media so that teaching and learning activities become effective. The purpose of this community service is to determine the process of developing animated video learning media, the feasibility of the media, and student responses to animated video learning media and to increase sales. The results obtained from the implementation of this community service are that animated video learning media are suitable for use as an alternative learning media that will be more effective and can increase sales.
\end{abstract}

Keywords: Animated Videos; Learning Media; Sales Turnover

\begin{abstract}
Abstrak
Kemajuan ilmu pengetahuan dan teknologi turut mempengaruhi kemajuan dan perkembangan di berbagai bidang termasuk pendidikan. Guru harus mampu menciptakan pembelajaran yang menarik dan berpotensi menciptakan semangat belajar siswa. Berdasarkan hasil identifikasi awal kepada salah satu dewan guru SMA Muhammadiyah 3 Surabaya, diketahui bahwa salah satu permasalahan yang dihadapi guru saat ini adalah kesulitan untuk menyediakan media pembelajaran yang efektif. Hal tersebut dapat terwujud di antaranya melalui penggunaan video animasi dalam pembelajaran. Media pembelajaran merupakan bagian terpenting dalam pelaksanaan kegiatan evaluasi pembelajaran. Media video animasi merupakan suatu inovasi agar kegiatan belajar mengajar menjadi efektif. Tujuan dari kegiatan pengabdian kepada masyarakat ini adalah untuk mengetahui proses pengembangan media pembelajaran video animasi, kelayakan media, dan respons siswa terhadap media pembelajaran video animasi serta dapat meningkatkan penjualan. Hasil yang diperoleh dari pelaksanaan pengabdian kepada masyarakat ini yaitu media pembelajaran video animasi layak digunakan sebagai alternatif media pembelajaran sehingga akan lebih efektif dan bisa menaikkan penjualan.
\end{abstract}

Kata kunci: Media Pembelajaran; Penjualan; Video Animasi

\section{Pendahuluan}

Pendidikan merupakan implementasi untuk mencerdaskan kehidupan bangsa. Proses pembelajaran memegang peranan yang sangat penting pada proses belajar siswa untuk mencapai tujuan belajar. Keberhasilan proses pembelajaran dipengaruhi oleh beberapa aspek, antara lain penggunaan strategi dalam pembelajaran di kelas. Peran guru dalam proses pembelajaran bukan satu-satunya sumber dan pusat dari pembelajaran (Oya \& Budiningsih, 2014). 
Motivasi memegang peranan penting dalam proses belajar siswa. Menurut (Ormrod, 2009), motivasi dapat meningkatkan prakarsa (inisiasi) dan kegigihan terhadap berbagai aktivitas. Siswa akan cenderung memulai sesuatu tugas yang diinginkan. "Motivation is defined as an internal state hat arouses us to action, pushes us in particular directions, and keeps us engaged in certain activities." Motivasi didefinisikan sebagai keadaan internal yang membangkitkan diri untuk bertindak, mendorong ke arah tertentu, dan melibatkan dalam kegiatan tertentu (Elliott dkk., 2000).

Keberhasilan suatu pembelajaran tentu tidak hanya pada tercapainya tujuan pembelajaran pada aspek kognitif saja, melainkan juga dengan munculnya perilaku siswa yang berkarakter. Siswa yang berkarakter sangatlah penting karena karakter merupakan perilaku moral yang akan membentuk manusia pada masa yang akan datang. Karakter terdiri atas nilai-nilai operatif, nilainilai yang berfungsi dalam praktik (Lickona, 2013). Karakter tersebut tumbuh menjadi budi pekerti, sebuah batin yang diandalkan dan digunakan untuk merespons berbagai situasi dengan cara bermoral. Karakter akan terbentuk dan melekat pada diri sampai usia dewasa.

Media pembelajaran merupakan salah satu komponen dari sistem yang dirancang untuk mencapai tujuan pembelajaran. Secara rinci, komponen untuk mencapai tujuan pembelajaran tersebut terdiri atas: (1) tujuan, (2) bahan/materi ajar, (3) metode, (4) alat/media, dan (5) evaluasi (Ali, 1992). Sebuah sistem akan berjalan baik tergantung efektivitas komponen-komponen yang terdapat di dalamnya. Media pembelajaran sebagai salah satu komponen dalam sistem itu, mempunyai fungsi sebagai sarana komunikasi nonverbal. Media mutlak harus ada atau dimanfaatkan di dalam setiap pembelajaran.

Pada masa pandemi COVID-19 ini, jual beli secara online menjadi media yang tepat dan efektif untuk dapat meningkatkan penjualan, salah satunya berupa produk video animasi. Saat ini, video animasi sangat digemari oleh masyarakat saat berada di rumah. Hal tersebut karena video animasi dapat menarik perhatian seluruh masyarakat yang melihatnya.

Pengabdian kepada masyarakat ini dibatasi pada masalah rendahnya motivasi belajar siswa, belum terlihatnya karakter kerja keras pada diri siswa, belum maksimalnya pemanfaatan media pembelajaran, dan tingginya kebutuhan guru akan media video animasi. Berdasarkan masalah yang dipaparkan tersebut, dibutuhkan suatu pelatihan khusus yang dapat memfasilitasi siswa-siswa SMA Muhammadiyah 3 Surabaya untuk dapat mengoptimalkan penggunaan media pembelajaran, khususnya yang interaktif dan menarik perhatian siswa. Meskipun demikian, dapat dikatakan bahwa salah satu fungsi utama media pengajaran adalah sebagai alat bantu mengajar yang turut mempengaruhi iklim, kondisi, dan lingkungan belajar yang ditata dan diciptakan oleh guru. Aplikasi yang dapat digunakan untuk membuat media pembelajaran adalah Flipaclip (2012).

Flipaclip adalah sebuah aplikasi Android yang bisa digunakan untuk membuat animasi sederhana. Flipaclip mampu membuat pengguna menghidupkan kembali masa kecil dan mengekspresikan kreativitas atau keterampilan profesional dalam cara yang jauh lebih dingin. Pengguna bisa membuat kartun menggunakan animasi frame-by-frame. Cara kerjanya seperti flip book, akan tapi lebih mudah dan amazing.

Dengan demikian, pengabdian kepada masyarakat ini difokuskan pada pengembangan media video animasi dengan materi Pelatihan pembuatan media pembelajaran untuk sisewa menggunakan video animasi guna meningkatkan penjualan di SMA Muhammadiyah 3 Surabaya.

\section{Metode Pelaksanaan}

Kegiatan pengabdian kepada masyarakat yang dilakukan oleh tim dosen dari Program Studi Teknik Informatika, Universitas Wijaya Kusuma Surabaya bekerja sama dengan tim guru SMA Muhammadiyah 3 Surabaya melakukan salah satu upaya pengembangan iptek dalam proses pembelajaran. Dengan memanfaatkan produk iptek berupa video animasi sebagai media inovatif dan kreatif dalam proses pembelajaran, akan mampu meningkatkan motivasi siswa dalam belajar. 


\subsection{Waktu, Lokasi, dan Pelaksanaan}

Kegiatan ini dilaksanakan pada 21 Oktober 2020. Pelatihan ini dilaksanakan secara daring. Peserta pelatihan terdiri dari semua siswa beserta guru SMA Muhammadiyah 3 Surabaya. Jumlah peserta yang mengikuti pelatihan ini yaitu 50 orang.

\subsection{Metode Kegiatan}

Pelatihan ini menerapkan penggunaan media daring berbasis Zoom. Pemateri mengisi materi menggunakan multimedia (slide) PowerPoint dan diberlakukan diskusi dan tanya jawab selama presentasi berlangsung. Hal ini dilakukan untuk menjawab pertanyaan secara cepat dan membuat suasana pelatihan sedikit santai. Metode curah pendapat, demonstrasi, dan audio-visual juga digunakan dalam memaparkan materi pelatihan. Pada akhir acara, pemateri melemparkan pertanyaan kepada siswa dengan bonus doorprize, membuat suasana pelatihan bertambah meriah.

Tahap awal kegiatan pengabdian kepada masyarakat ini ialah mengumpulkan literatur tentang pembuatan animasi. Pada tahap ini, tim dosen Universitas Wijaya Kusuma Surabaya juga intensif berkomunikasi dengan dewan guru SMA Muhammadiyah 3 Surabaya untuk menanyakan pengalaman dan hambatan yang mereka temukan dalam membuat media pembelajaran video animasi. Tim dosen Universitas Wijaya Kusuma Surabaya juga menanyakan bagaimana tanggapan siswa SMA Muhammadiyah 3 Surabaya terhadap media pembelajaran video animasi. Dari hasil observasi tersebut, diketahui bahwa sebagian besar siswa belum dapat menggunakan media pembelajaran video animasi yang sesuai dengan kondisi terkini.

Tahap kedua dalam kegiatan ini adalah pembuatan modul pelatihan. Modul ini berisi pengertian dan macam-macam tool/program dalam membuat video animasi, tata cara instalasi tool/program, langkah-langkah kerja dalam pembuatan animasi yang disertai dengan petunjuk gambar, serta contoh animasi yang terbentuk.

Tahap ketiga yang dilakukan adalah pelaksanaan kegiatan pelatihan pembuatan media pembelajaran dengan video animasi di SMA Muhammadiyah 3 Surabaya. Dalam pelaksanaan kegiatan, peserta diharapkan aktif dan antusias mengikuti rangkaian kegiatan pelatihan.

\section{Hasil dan Pembahasan}

Dalam pelaksanaan kegiatan, peserta aktif dan antusias mengikuti rangkaian kegiatan pelatihan. Hasil dari kegiatan pengabdian kepada masyarakat yang berupa pembuatan video animasi dapat meningkatkan penjualan. Para peserta pelatihan memberikan respons positif atas terselenggaranya program pelatihan ini. Beberapa tanggapan positif seluruhnya diberikan oleh peserta kepada materi dan pemateri pelatihan ini. Berdasarkan hasil survei, dapat disimpulkan bahwa peserta pelatihan sangat puas dengan pelayanan dan pembekalan materi dari fasilitator. Respon positif ini akan dijadikan bahan untuk tindak lanjut pelatihan berikutnya.

Foto-foto pelaksanaan kegiatan pengabdian masyarakat program studi Teknik Informatika, Fakultas Teknik, Universitas Wijaya Kusuma Surabaya dapat dilihat pada Gambar 1-10. Gambar 1 mengilustrasikan tampilan aplikasi Zoom saat awal pelaksanan kegiatan pengabdian masyarakat yang dilaksanakan secara daring. Gambar 2 mengilustrasikan pembukaan kegiatan pengabdian masyarakat yang dilakukan oleh tiga program bidang studi, yaitu program studi Teknik Sipil, Teknologi Industri Pertanian, dan Teknik Informatika. 




Gambar 1. Tampilan Awal atau Background Kegiatan pada Aplikasi Zoom

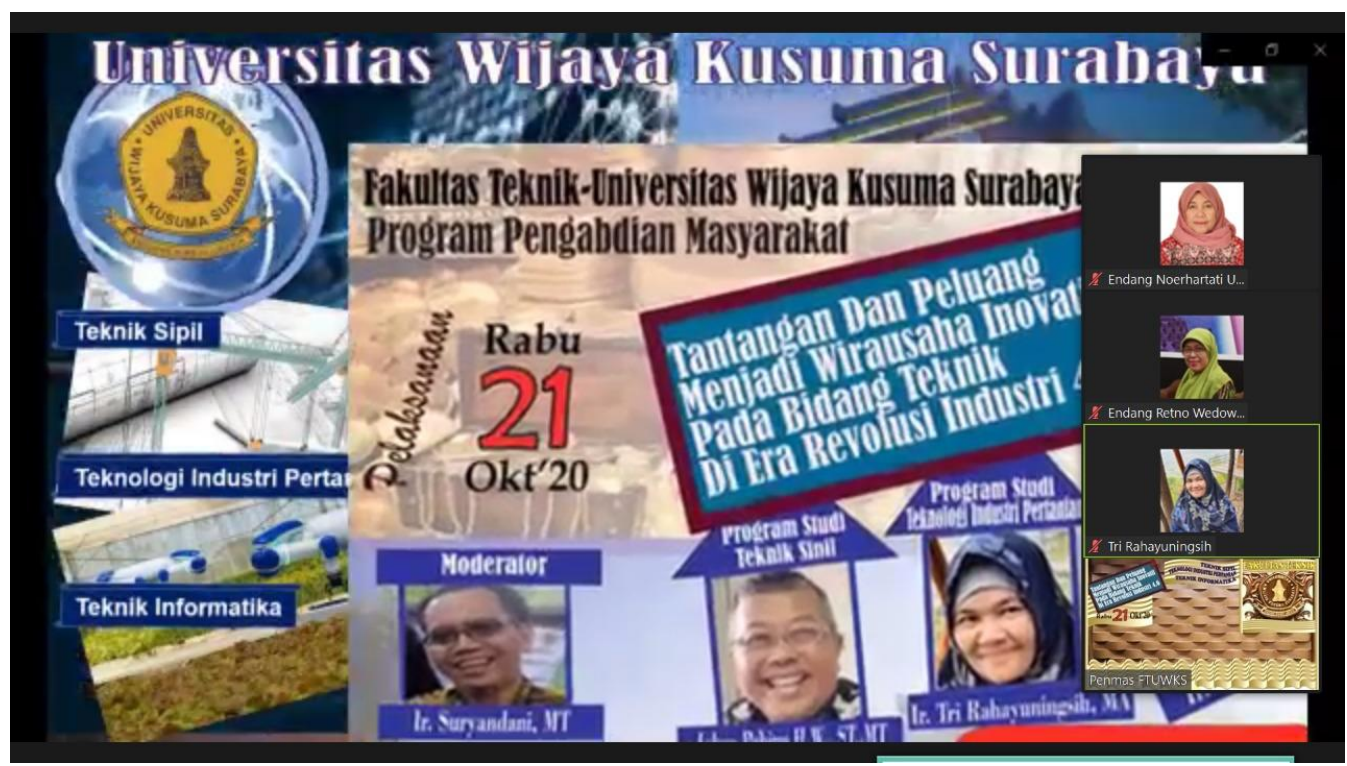

Gambar 2. Pembukaan Kegiatan Pengabdian Masyarakat oleh Tiga Program Studi

Gambar 3 mengilustrasikan pembukaan acara pengabdian masyarakat oleh program studi Teknik Informatika yang antara lain berisi kegiatan menyanyikan lagu Indonesia Raya. Gambar 4 mengilustrasikan tampilan atau background peserta kegiatan, yakni SMA Muhammadiyah 3 Surabaya. 


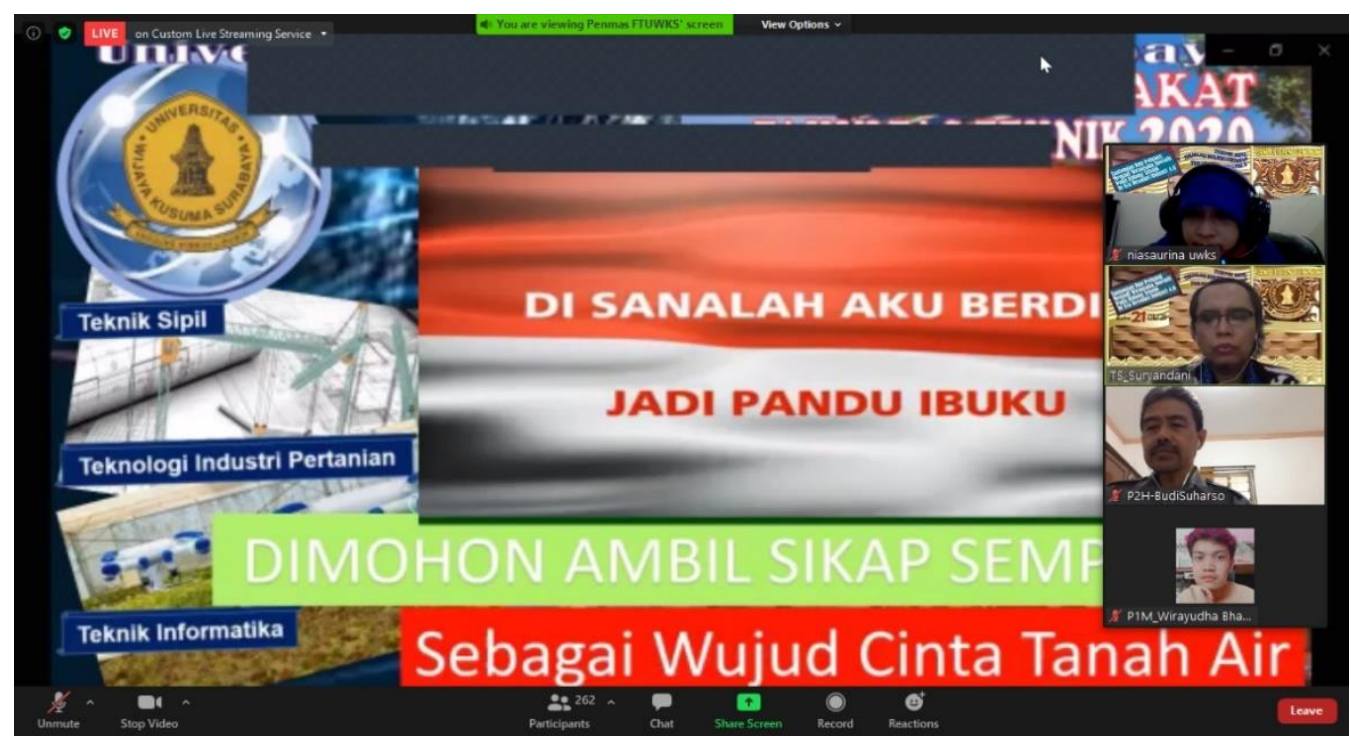

Gambar 3. Pembukaan Acara Pengabdian Masyarakat oleh Program Studi Teknik Informatika

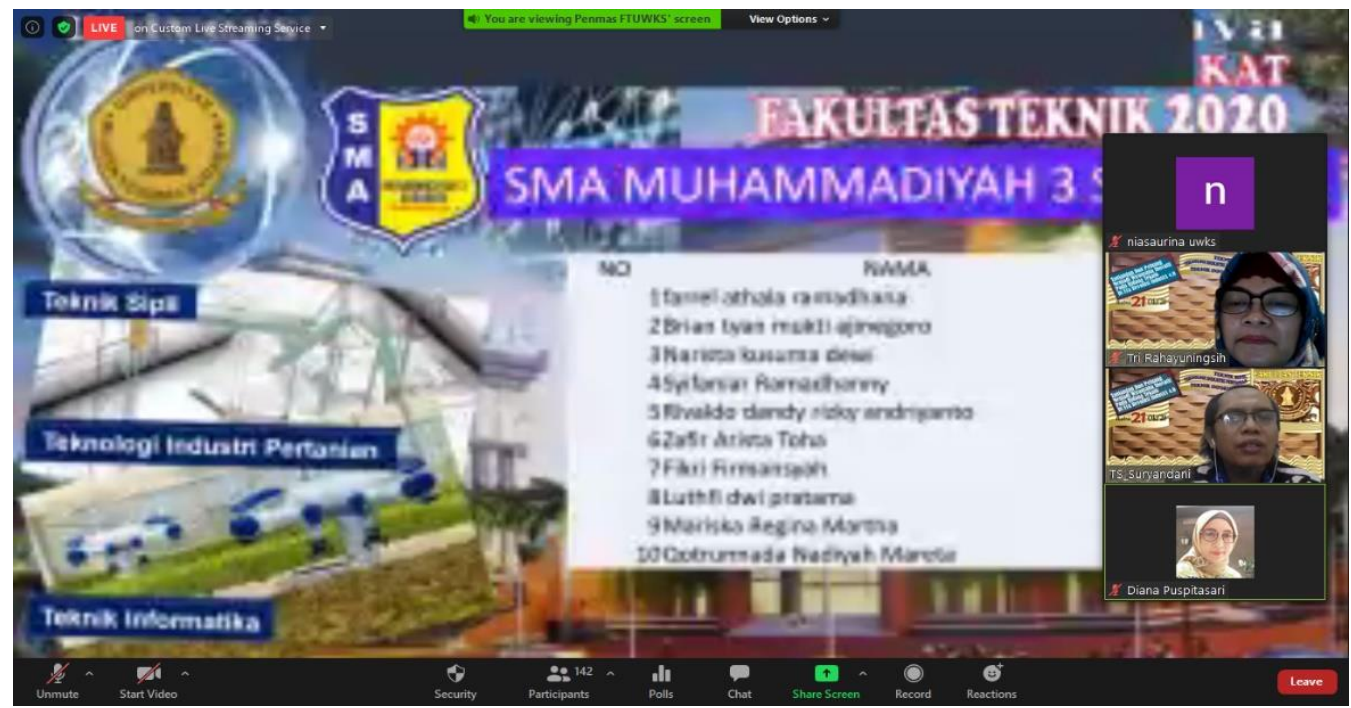

Gambar 4. Tampilan atau Background SMA Muhammadiyah 3 Surabaya

Gambar 5 mengilustrasikan pembukaan kegiatan berupa sambutan oleh Dekan Fakultas Teknik. Pada Gambar 6, dapat dilihat moderator acara yang sedang memimpin acara. 


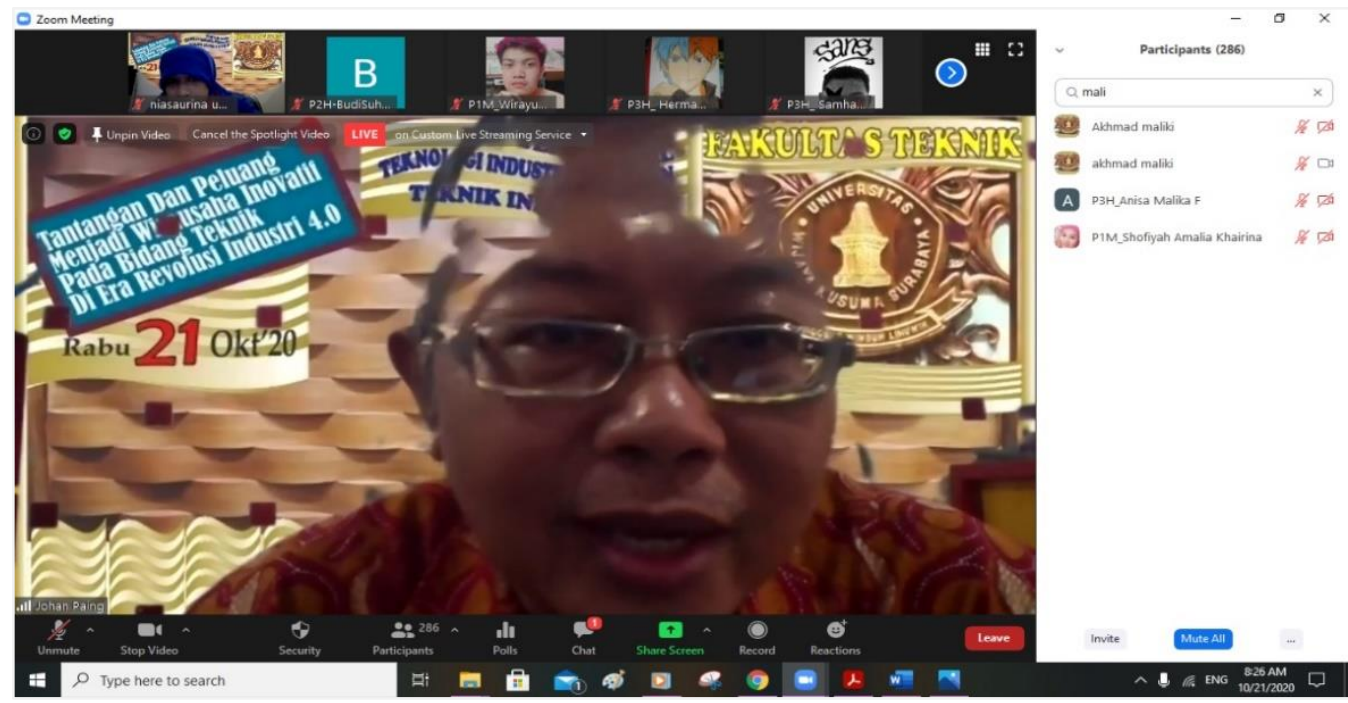

Gambar 5. Pembukaan Acara Dimulai dengan Sambutan dari Dekan Fakultas Teknik
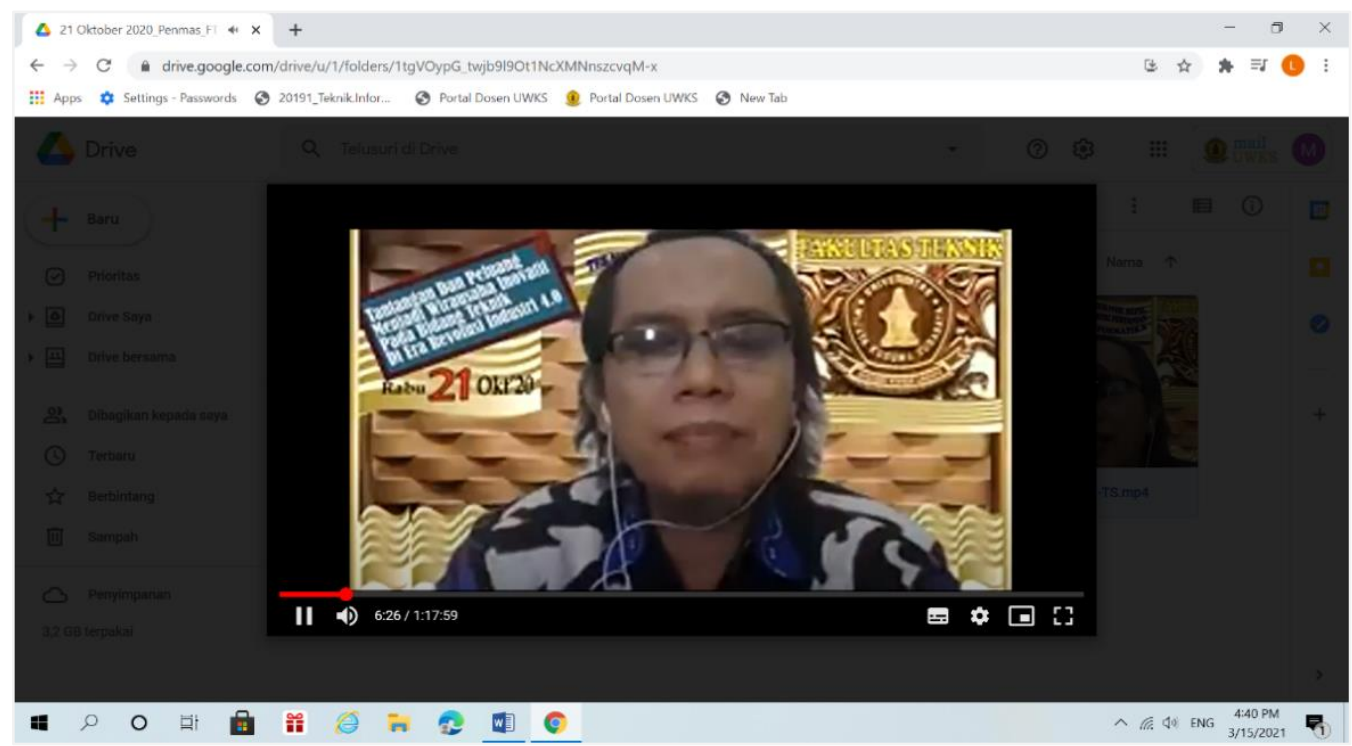

Gambar 6. Moderator Acara Pengabdian Masyarakat

Gambar 7 mengilustrasikan kegiatan inti, yakni pelatihan oleh pembicara atau narasumber dari dosen program studi Teknik Informatika. Gambar 8 mengilustrasikan kegiatan pelatihan dalam bentuk tutorial pemanfaatan aplikasi Flipaclip, langkah demi langkah. Gambar 9 dan 10 mengilustrasikan tangkapan layar peserta kegiatan yang dimunculkan dalam bentuk grid sebagai bentuk dokumentasi akhir kegiatan. 


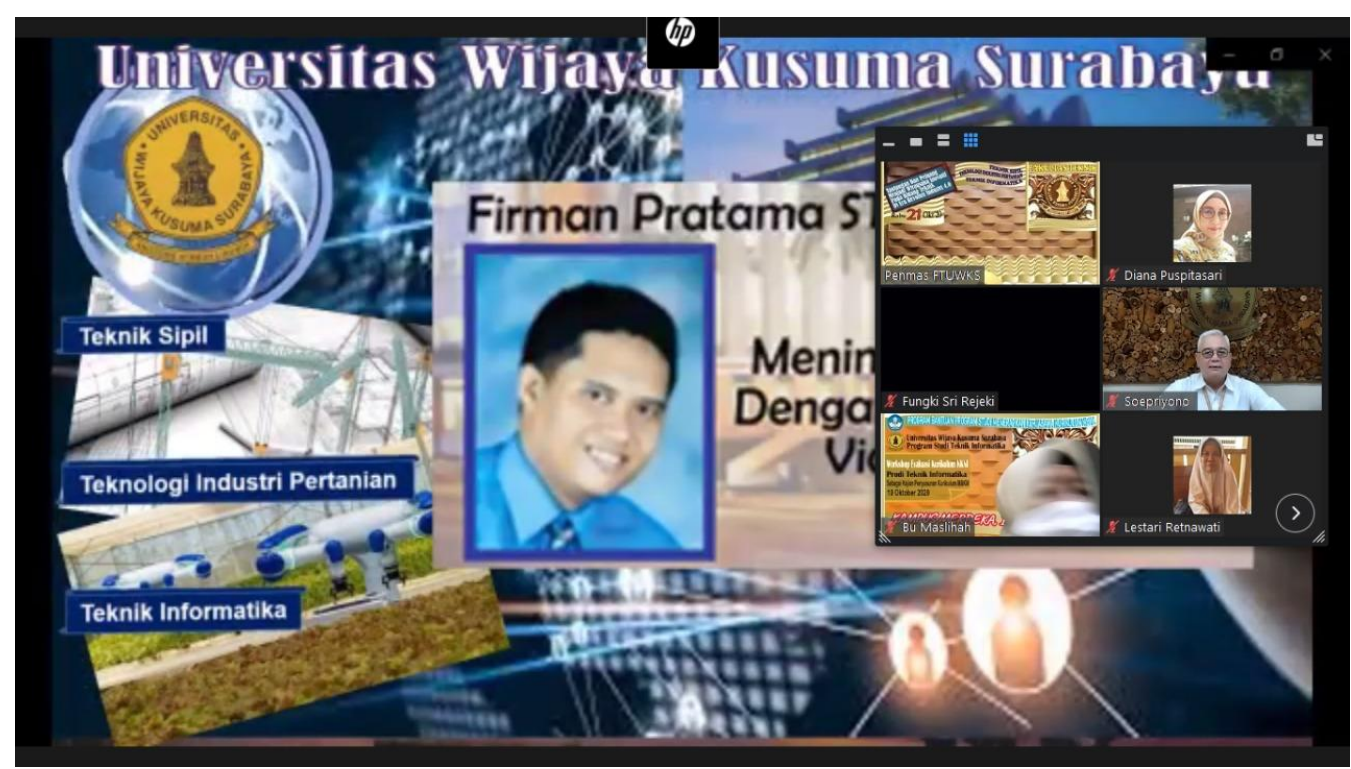

Gambar 7. Pelatihan oleh Pembicara atau Narasumber

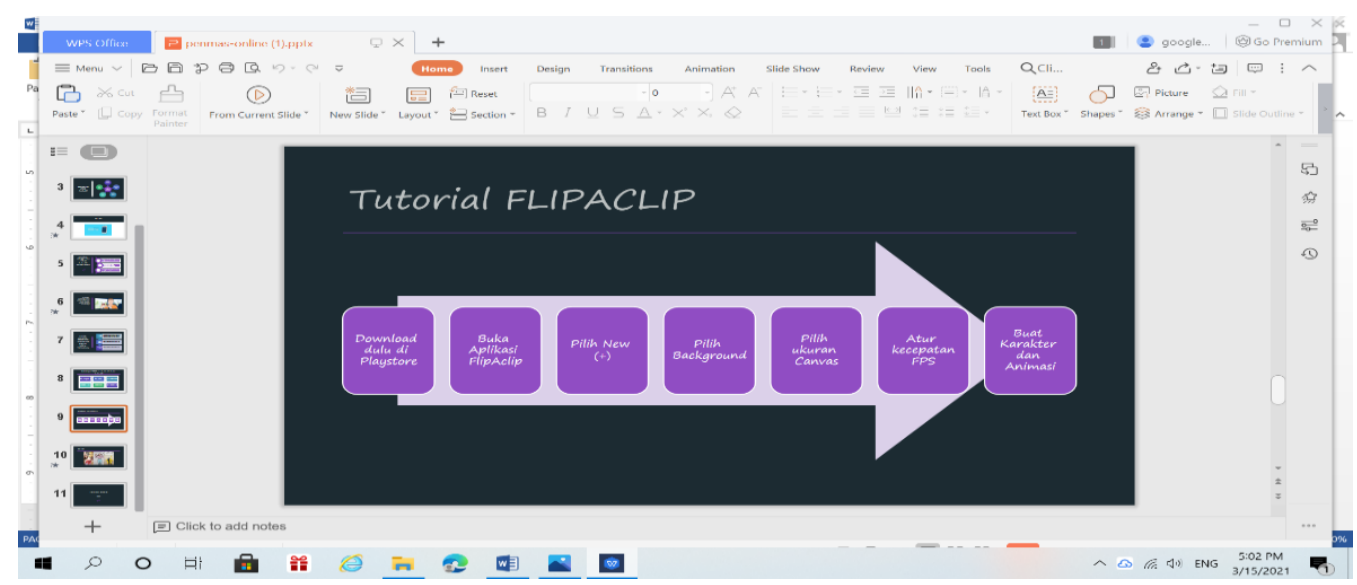

Gambar 8. Langkah-Langkah atau Tutorial Media Pembelajaran Video Animasi Flipaclip



Gambar 9. Tampilan Peserta Pengabdian Masyarakat 


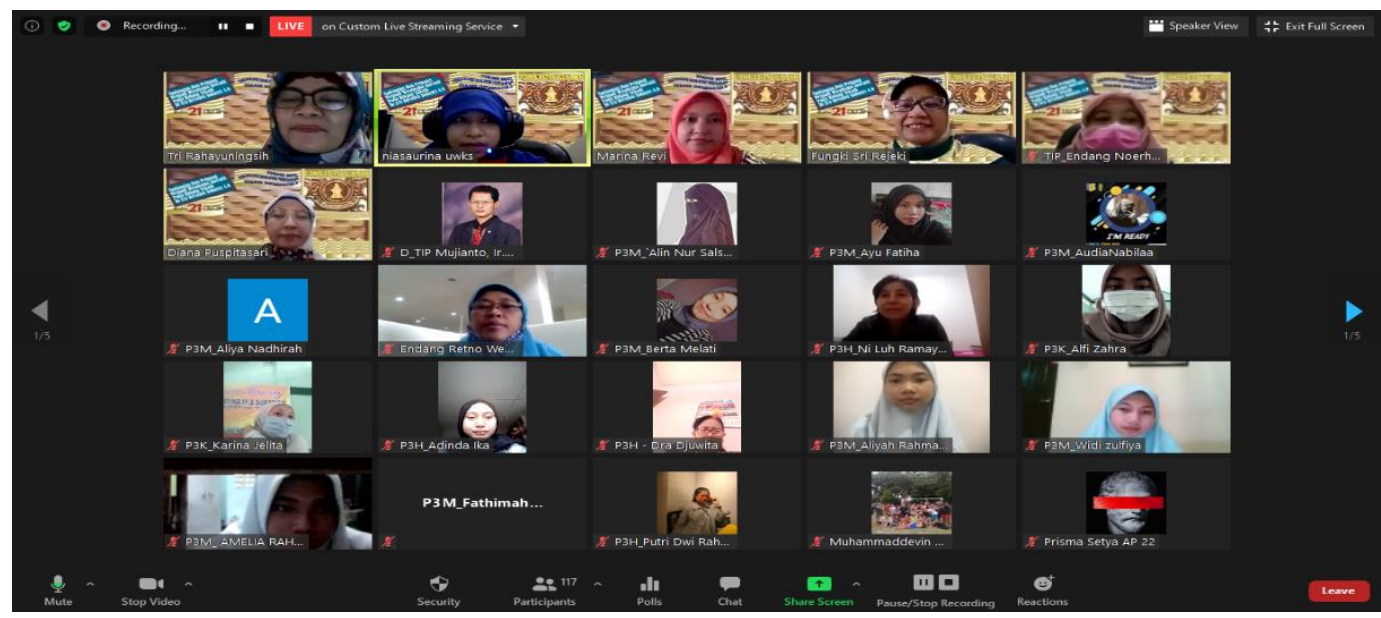

Gambar 10. Tampilan Peserta Pengabdian Masyarakat (lanjutan)

\section{Kesimpulan}

Berdasarkan kegiatan-kegiatan yang telah dilakukan, kesimpulan yang diperoleh antara lain kegiatan ini memberi pengetahuan tentang bagaimana melakukan penjualan online melalui video animasi. Selain itu, hasil kegiatan ini berupa tips dan trik pembuatan video animasi untuk meningkatkan penjualan.

Harapan dari peserta, ke depan, pelatihan-pelatihan sejenis dapat terus dilakukan. Dari fasilitator, pelatihan yang diberikan dapat menjangkau lebih banyak peserta dengan fasilitas yang lebih baik lagi. Pelatihan yang diberikan ke depannya diharapkan juga dapat dilakukan dengan waktu yang lebih lama agar materi yang dibahas dapat dipaparkan dengan lebih mendalam sehingga dapat meningkatkan motivasi belajar siswa, khususnya di SMA Muhammadiyah 3 Surabaya.

\section{Daftar Pustaka}

Ali, M. (1992). Guru dalam Proses Belajar Mengajar. Sinar Baru.

Elliott, S. N., Travers, J. F., Kratochwill, T. R., \& Littlefield Cook, J. (2000). Educational psychology: Effective teaching, effective learning (3 ed.). McGraw-Hill.

Flipaclip. (2012). [Android]. Visual Blasters LLC.

https://play.google.com/store/apps/details?id=com.vblast.flipaclip

Lickona, T. (2013). Educating for Character (Lita S, Penerj.). Nusa Media.

Ormrod, J. E. (2009). Educational Psycology Developing (Penerbit Erlangga, Penerj.; Vol. 1). Gelora Aksara Pratama.

Oya, R., \& Budiningsih, C. (2014). PENINGKATKAN MOTIVASI DAN HASIL BELAJAR BAHASA INDONESIA MENGGUNAKAN MODEL PEMBELAJARAN KREATIF DAN PRODUKTIF. Jurnal Prima Edukasia, 2(1), 116-126. https://doi.org/10.21831/jpe.v2i1.2649 


\section{Afiliasi:}

Lestari Retnawati*, Firman Pratama, Tjatursari Widiartin, Nonot Wisnu Karyanto, Anang Kukuh Adisusilo

Universitas Wijaya Kusuma Surabaya

Jalan Dukuh Kupang XXV, Surabaya

E-mail : lestariretnawati10@gmail.com*,firmanp83@gmail.com,widiartin@gmail.com, nonotwik@gmail.com, anang65@uwks.ac.id 
JPP IPTEK (Jurnal Pengabdian dan Penerapan IPTEK), Mei 2021, Volume 5, Nomor 1

- Halaman ini sengaja dikosongkan - 